\title{
Stimulation of both estrogen and androgen receptors maintains skeletal muscle mass in gonadectomized male mice but mainly via different pathways
}

\author{
Johan Svensson, Sofia Movérare-Skrtic, Sara Windahl, Charlotte Swanson \\ and Klara Sjögren
}

Division of Endocrinology, Department of Internal Medicine, Institute of Medicine, Sahlgrenska University Hospital, SE-41345 Göteborg, Sweden

(Correspondence should be addressed to K Sjögren; Email: klara.sjogren@medic.gu.se)

\begin{abstract}
Testosterone is a major regulator of muscle mass. Little is known whether this is due to a direct stimulation of the androgen receptor $(A R)$ or mediated by aromatization of testosterone to estradiol $\left(E_{2}\right)$, the ligand for the estrogen receptors (ERs), in peripheral tissues. In this study, we differentiated between the effects mediated by AR and ER by treating orchidectomized (orx) male mice for 5 weeks with $\mathrm{E}_{2}$ or the non-aromatizable androgen dihydrotestosterone (DHT). Both $E_{2}$ and DHT increased muscle weight and lean mass, although the effect was less marked after $E_{2}$ treatment. Studies of underlying mechanisms were performed using gene transcript profiling (microarray and real-time PCR) in skeletal muscle, and they demonstrated that $\mathrm{E}_{2}$ regulated 51 genes and DHT regulated 187 genes, with 13 genes $(=25 \%$ of $\mathrm{E}_{2}$-regulated genes) being regulated by both treatments. Both $\mathrm{E}_{2}$ and $\mathrm{DHT}$ altered the expression of $F b x 032$, a gene involved in skeletal muscle atrophy, affected the IGF1 system, and regulated genes involved in angiogenesis and the glutathione metabolic process. Only $\mathrm{E}_{2}$ affected genes that regulate intermediary glucose and lipid metabolism, and only DHT increased the expression of genes involved in synaptic transmission and heme and polyamine biosynthesis. In summary, ER activation by $E_{2}$ treatment maintains skeletal muscle mass after orx. This effect is less marked than that of AR activation by DHT treatment, which completely prevented the effect of orx on muscle mass and was partly, but not fully, mediated via alternative pathways.
\end{abstract}

Journal of Molecular Endocrinology (2010) 45, 45-57

\section{Introduction}

Testosterone is a major regulator of body composition. Androgen deficiency is associated with decreased muscle mass, and testosterone supplementation increases muscle mass in hypogonadal men, HIVinfected men, and older men with low testosterone concentrations (Snyder et al. 1999, 2000, Kong \& Edmonds 2002). Also, in orchidectomized (orx) mice, testosterone treatment dose dependently increases the mass of individual muscles (Axell et al. 2006).

Both testosterone and the non-aromatizable androgen dihydrotestosterone (DHT) bind to and activate the androgen receptor (AR; MacLean et al. 1997). The $A R$ gene is expressed widely in muscle including myoblasts, myofibers, and satellite cells (Chen et al. 2005). The AR is also expressed in motor neurons which may contribute to the regulation of muscle mass and function (Yang \& Arnold 2000). Several different AR knockout (ARKO) mouse models have been reported. In one of these models, muscle mass was unchanged, whereas in another model, decreased muscle mass and impaired muscle function were observed in male ARKO mice but not in female ARKO mice (Lin et al. 2005, MacLean et al. 2008). Ophoff et al. (2009) recently reported that a myocytespecific knockout of the AR in male mice resulted in decreased lean mass and a conversion of fast towards slow muscle fibers, without affecting muscle strength or fatigue. In their study, similar results were obtained in male mice with ubiquitous ARKO.

Testosterone can exert its effect either directly by stimulation of the AR or via aromatization in target tissues to estradiol $\left(\mathrm{E}_{2}\right)$, the ligand for the estrogen receptors (ERs) $\alpha$ and $\beta$ (also known as ESR1 and ESR2 respectively). Muscle from both men and women contains aromatase enzyme activity (Matsumine $e t$ al. 1986). The extent to which the actions of testosterone in muscle are a consequence of AR or ER activation or both is not clear.

Skeletal muscle myoblasts, myotubes, and mature fibers all express functional ERs, indicating a direct effect of estrogen in muscle (Kahlert et al. 1997, Barros et al. 2006). Women after menopause have decreased lean body mass, which can be reversed by estrogen 
replacement therapy (Sorensen et al. 2001). In animals, estrogen has been shown to regulate skeletal muscle mass in developing livestock, rats, and mice (Trenkle 1976, Kobori \& Yamamuro 1989, McCormick et al. 2004, Moran et al. 2007). Furthermore, ovariectomy decreases rat skeletal muscle mass recovery, and estrogen replacement benefits atrophied muscle mass recovery (Brown et al. 2005, Sitnick et al. 2006). Male mice lacking ER $\beta$ also exhibit altered muscle function (Glenmark et al. 2004).

By studying the effects on lean mass and weight of individual muscles and comparing gene expression after ER- and AR-mediated stimulation in muscle of gonadectomized mice, this study aimed to investigate whether the effect of testosterone on lean tissue could be due to a direct stimulatory effect on the AR or due to aromatization of testosterone to $\mathrm{E}_{2}$.

\section{Materials and methods}

\section{Animals and study design}

Mice were on a C57BL/ 6 background, and had free access to fresh water and soy-free food pellets (R70, Lactamin AB, Stockholm, Sweden or 2016, Harlan Teklad, UK). The ethics committee at the University of Gothenburg approved this study.

At 12 weeks of age, male mice were orx, and then treated for 5 weeks with DHT $(45 \mu \mathrm{g} /$ day $), \mathrm{E}_{2}$ $(0.05 \mu \mathrm{g} /$ day), or vehicle (veh) administered via subcutaneous silastic implants (Silclear Tubing; Degania Silicone, Ltd, Jordan Valley, Israel) in the cervical region (Vandenput et al. 2002). Gonadectomy and implantation of pellets were performed during the same surgical session for all experimental groups. At the end of the treatment period, dual X-ray absorption (DXA) measurements were performed in vivo ( $n=6-8$ in each group). Then, $\mathrm{m}$. quadriceps and $\mathrm{m}$. gastrocnemius together with various organs were dissected, and their wet weights were determined. Blood was collected for analyses of serum insulin-like growth factor 1 (IGF1) concentration, and distal femur trabecular volumetric bone mineral density (vBMD) was determined ex vivo using peripheral quantitative computerized tomography (pQCT) $(n=6-8$ in each group). In addition, total RNA was isolated from snap-frozen $\mathrm{m}$. gastrocnemius for analyses using microarray ( $n=5$ in each group).

To determine the short-term effects of the hormone treatments on the expression of selected genes in muscle, a similar experiment as that described above was performed, but with a treatment period of only 1 week. Total RNA was isolated from snap-frozen $\mathrm{m}$. gastrocnemius and $\mathrm{m}$. levator ani for analyses using real-time PCR (RT-PCR).

\section{DXA analysis}

Body composition of mice was measured by DXA using the Lunar PIXImus Mouse Densitometer (Wipro GE Healthcare, Madison, WI, USA) with the mice under inhalation anesthesia with isoflurane (Forane; Abbot Scandinavia).

\section{Peripheral quantitative computerized tomography}

Distal femur trabecular vBMD was measured ex vivo using the Stratec pQCT XCT Research M (software version 5.4B; Norland Medical Systems Inc., White Plains, NY, USA) operating at a resolution of $70 \mu \mathrm{m}$ (Windahl et al. 1999). The pQCT scan was positioned in the metaphysis at a distance from the distal growth plate corresponding to $3 \%$ of the total length of the femur, and the trabecular bone region was defined as the inner $45 \%$ of the total cross-sectional area.

\section{DNA microarray analysis}

Total RNA was isolated from snap-frozen $\mathrm{m}$. gastrocnemius using RNeasy Mini Kit including an on-column DNase digestion step using the RNase-free DNase set (Qiagen). The mRNA samples derived from each individual mouse were reverse transcribed into cDNA, labeled, and analyzed using DNA microarray (mouse expression set 430; Affymetrix, Santa Clara, CA, USA) ( $n=5$ in each group). Preparation of labeled cRNA, hybridization, and staining were done according to the Affymetrix Gene Chip expression analysis manual. The stained probe array was scanned, and the resultant image was captured as a data image (.CEL) file. The signal intensities for the $\beta$-actin $(A c t b)$ and the Gapdh genes were used as the internal quality controls. The ratio of fluorescent intensities for the $5^{\prime}$ end the $3^{\prime}$ end of these housekeeping genes was $<3$. The microarray data can be accessed at EMBL-EBI ArrayExpress repository, ArrayExpress accession: E-MEXP-2192.

\section{Bioinformatics}

To correct for variation between GeneChips, the signal data of CEL files of Affymetrix mouse expression set 430 chips were quantile normalized, with probe set intensities calculated using the Robust Multiarray Average (Irizarry et al. 2003). For each gene, a $t$-test was used to estimate the effect of treatment. A gene was considered regulated if it demonstrated a fold change $\geq 1.5$ and $P \leq 0.05$ in response to $\mathrm{E}_{2}$ or DHT treatment compared with the veh. The mouse expression set 430 annotation file dated August 2008 was downloaded 
from Affymetrix, from which the gene title, gene symbol, gene ontology (GO) biological process, GO cellular component, and GO molecular functions of the regulated genes were identified. The genes were then grouped by their unique GO classifications (biological process, cellular component, and molecular function).

\section{Quantitative RT-PCR analysis}

Total RNA was isolated from snap-frozen $\mathrm{m}$. gastrocnemius. The RT-PCR analysis was performed using the ABI Prism 7000 Sequence Detection System (PE Applied Biosystems, Stockholm, Sweden). The mRNA abundance of each gene was calculated using the 'standard curve method' (User Bulletin 2; PE Applied Biosystems), and was adjusted for the expression of $18 \mathrm{~S}$. Primer and probe sequences are available upon request.

\section{Serum assay}

Serum IGF1 level was measured by a double-antibody IGF-binding protein-blocked RIA (Mediagnost, Tubingen, Germany).

\section{Statistical analyses}

All the descriptive statistical results are presented as the means \pm s.E.M. Between-group differences were calculated using unpaired $t$-tests. Comparisons between multiple groups were done using a one-way ANOVA followed by the Student-Newman-Keuls post hoc test. A two-tailed $P \leq 0.05$ was considered significant.

\section{Results}

\section{Comparison of the effects of AR and ER stimulation in male mice}

To compare the importance of AR versus ER stimulation in muscle in male mice, 12-week-old male orx mice were treated for 5 weeks with either veh, the non-aromatizable androgen DHT, or $\mathrm{E}_{2}$.

\section{Seminal vesicles and bone}

To test whether the DHTand $\mathrm{E}_{2}$ doses were physiological, we studied the effects on seminal vesicles and trabecular vBMD. The DHT dose used ( $45 \mu \mathrm{g} /$ day) was physiological, since it completely prevented the orx-induced loss of weight of the seminal vesicles (Fig. 1A). As expected, $\mathrm{E}_{2}(0.05 \mu \mathrm{g} /$ day $)$ had no effect on the weight of the seminal vesicles (Fig. 1A). Both $\mathrm{E}_{2}$ and DHT prevented the orx-induced reduction in trabecular vBMD almost completely as measured using pQCT (Fig. 1B).
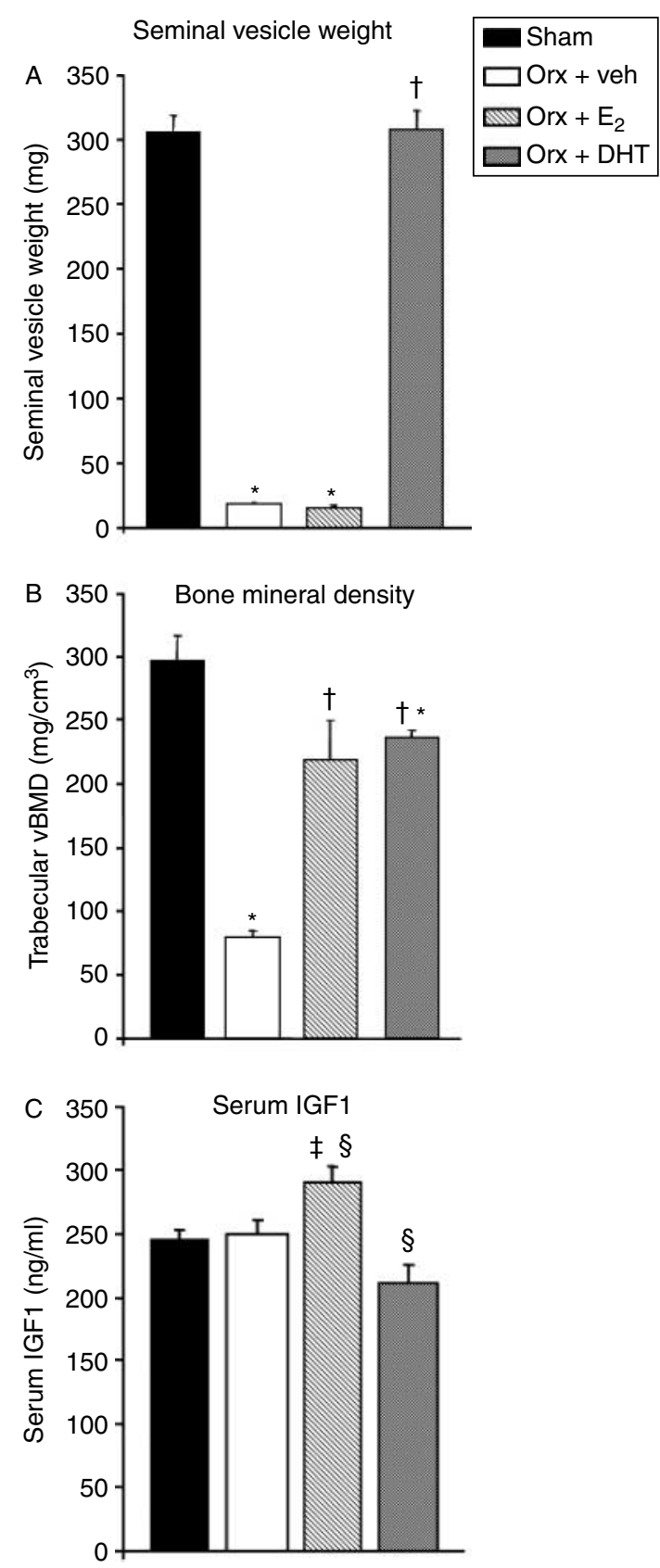

Figure 1 Seminal vesicle weight $(A)$, trabecular volumetric bone mineral density $(B)$, and serum IGF1 $(C)$ in 12-week-old male mice that were either sham-operated or orchidectomized (orx) and then treated for 5 weeks with vehicle (veh), dihydrotestosterone (DHT) $(45 \mu \mathrm{g} /$ day $)$, or $17 \beta$-estradiol $\left(E_{2}\right)(0.05 \mu \mathrm{g} /$ day $)$. Values are given as means \pm S.E.M., $n=6-8$ in each group. ${ }^{*} P \leq 0.01$ versus sham; ${ }^{\dagger} P \leq 0.01$ versus orx + veh; ${ }^{\ddagger} P \leq 0.05$ versus sham; ${ }^{\S} P \leq 0.05$ versus orx + veh; $P$ values are based on a one-way ANOVA followed by the Student-Newman-Keuls post hoc test. 


\section{Serum IGF1}

Orx had no effect on serum IGF1 levels. $\mathrm{E}_{2}$ treatment increased serum IGF1 by $18.4 \%(P \leq 0.05$ versus sham, Fig. 1), whereas DHT treatment did not differ significantly from the sham-operated controls (Fig. 1).

\section{Lean tissue and muscle weight}

As measured using DXA, there was a loss of whole-body lean tissue mass by $9.4 \%$ after orx $(P \leq 0.01$ versus sham) that was prevented partly by $\mathrm{E}_{2}$ and completely by DHT (Fig. 2). E $E_{2}$ treatment resulted in an increased lean mass by $3.9 \% \quad(P \leq 0.05$ versus orx + veh $)$, and DHT treatment resulted in even further increased lean mass $\left(5 \cdot 6 \%\right.$ over orx $+\mathrm{E}_{2}, P \leq 0 \cdot 05$, and $9 \cdot 7 \%$ over orx + veh, $P \leq 0 \cdot 01)$. These results were confirmed by dissection and weighing of $\mathrm{m}$. quadriceps and $\mathrm{m}$. gastrocnemius (Fig. 2).

\section{The effects of $E_{2}$ and DHT treatments on gene expression in skeletal muscle}

Microarray analyses were performed on gastrocnemius muscle samples from individual mice $(n=5$ in each group) to compare global gene expression after treating orx mice for 5 weeks with either DHT or $\mathrm{E}_{2}$. Genes regulated by $\mathrm{E}_{2}$ or DHT (fold change $\geq 1.5$ and $P \leq 0.05$ versus veh) were assigned to several functional categories (Table 1). A complete catalog of these genes is published as supplementary data (Supplementary Table 1, see section on supplementary data given at the end of this article). DHT regulated 187 (133 up-regulated and 54 down-regulated) genes in muscle (Table 1). Fewer genes $(n=51)$ were regulated after $\mathrm{E}_{2}$ treatment (33 up-regulated and 18 down-regulated, Table 1). Although a treatment period of 5 weeks would mean that several of these genes may reflect secondary effects of hormone treatment, we refer to them as $\mathrm{E}_{2} / \mathrm{DHT}$-regulated genes for simplicity.

\section{Regulated genes in common for DHT and $E_{2}$}

DHT and $\mathrm{E}_{2}$ regulated different sets of genes, except 13 genes $\left(=25 \%\right.$ of $\mathrm{E}_{2}$-regulated genes) that were regulated by both treatments $(5 \cdot 8 \%$ of the total number of regulated genes, Table 2). Among them was Fbxo32, a gene encoding a muscle-specific F-box protein implicated in muscle atrophy that was up-regulated by both treatments. Five of the regulated genes had unknown function (Table 2).

\section{IGF1 signalling}

In muscle, $\mathrm{E}_{2}$ decreased the expression of $\operatorname{Ig} f 1$ (Table 3). The IGF1 signaling pathway includes many signaling molecules that are also important for signaling through the insulin receptor. $\mathrm{E}_{2}$ up-regulated one of these signaling molecules, Tbc1d1 (Table 3). DHT decreased the expression of Grb10, an inhibitor of IGF1 signaling, and Socs2, a suppressor of cytokine


Figure 2 Lean tissue that was measured by DXA (A) and wet weight of dissected quadriceps muscle $(B)$ and gastrocnemius muscle $(C)$ from 12-week-old male mice that were either sham-operated or orchidectomized (orx) and then treated for 5 weeks with vehicle (veh), dihydrotestosterone (DHT) (45 $\mu \mathrm{g} /$ day), or $17 \beta$-estradiol $\left(E_{2}\right)(0.05 \mu \mathrm{g} /$ day $)$. Values are given as means \pm S.E.M., $n=6-8$ in each group. ${ }^{\star} P \leq 0.01$ versus sham; ${ }^{\dagger} P \leq 0.01$ versus orx + veh; ${ }^{\ddagger} P \leq 0.05$ versus orx + veh; ${ }^{\S} P \leq 0.05$ versus orx $+\mathrm{E}_{2}$; ${ }^{\#} P \leq 0.01$ versus orx $+\mathrm{E}_{2}$. $P$ values are based on a one-way ANOVA followed by the Student-Newman-Keuls post hoc test. 
signaling. Furthermore, there was an increased expression of $\operatorname{Sh} p 2$, a phosphatase important for IGF1 signaling (Table 3 ).

\section{Fuel metabolism}

In muscle, $\mathrm{E}_{2}$ increased the expression of two genes involved in glucose metabolism: $P c x$, which encodes an enzyme converting pyruvate to oxaloacetate, and $F b p 2$, which encodes an enzyme active in glyconeogenesis. There was an increased expression of Ces3, which encodes a lipase mediating hydrolysis of triglycerides in muscle, and a decreased expression of Scd1, which encodes an enzyme active in triglyceride synthesis (Table 3). After DHT treatment, there was a decreased expression of Oxct1, which encodes an enzyme active in the catabolism of ketone bodies. DHT increased the expression of two genes involved in cholesterol metabolism: $N p c 1$, which encodes a protein that regulates the transport of cholesterol in the cell, and Vldl receptor, which encodes a peripheral lipoprotein receptor. Furthermore, DHT increased the expression of two genes encoding proteins involved in mitochondrial ATP synthesis-coupled proton transport, Ndufs4 and Cbr2 (Table 3).

Both $\mathrm{E}_{2}$ and DHT increased the expression of genes in the glutathione metabolic pathway that functions in the detoxification of hydrogen peroxide, protecting cells from oxidative damage (Table 3 ).

\section{Angiogenesis}

Both $\mathrm{E}_{2}$ and DHT affected the expression of genes involved in angiogenesis. $\mathrm{E}_{2}$ up-regulated Angpt1, which is a promoter of angiogenesis, and downregulated Thbsl, which is a negative regulator of

Table 1 Number of regulated genes in mouse skeletal muscle assigned to functional categories

\begin{tabular}{|c|c|c|c|c|c|c|c|}
\hline & & & ed $g$ & & $\operatorname{Reg}$ & gene & \\
\hline & GO ID & Total & Up & Down & Total & Up & Down \\
\hline Classification & & & & & & & \\
\hline Transcription & 0006350 & 3 & 2 & 1 & 18 & 12 & 6 \\
\hline Signal transduction & 0007165 & 8 & 4 & 4 & 23 & 17 & 6 \\
\hline Metabolic process & & & & & & & \\
\hline Glucose & 0006006 & 3 & 2 & 1 & - & - & - \\
\hline Ketone body & 0046950 & - & - & - & 1 & - & 1 \\
\hline Glutathione & 0006749 & 1 & 1 & - & 3 & 2 & 1 \\
\hline Others & & 1 & 1 & - & 3 & - & 3 \\
\hline Mitochondrial respiratory chain & 0005746 & - & - & - & 2 & 2 & - \\
\hline Protein metabolism and modification & & & & & & & \\
\hline Synthesis & & - & - & - & 4 & 1 & 3 \\
\hline Apoptosis & 0006915 & - & - & - & 2 & 2 & - \\
\hline Cell cycle & 0007049 & 2 & 1 & 1 & 4 & 2 & 2 \\
\hline Microtubule, cytoskeleton organization & 0000226 & - & - & - & 2 & 2 & - \\
\hline Angiogenesis & 0001525 & 2 & 1 & 1 & 1 & 1 & - \\
\hline Muscle contraction & 0006936 & 1 & - & 1 & 10 & - & 10 \\
\hline Polyamine biosynthetic process & 0006596 & - & - & - & 3 & 3 & - \\
\hline Extracellular matrix constituent & 0005201 & - & - & - & 8 & 6 & 2 \\
\hline Immune response & 0006955 & 2 & 1 & 1 & 2 & 2 & - \\
\hline Actin binding & 0003779 & - & - & - & 4 & 3 & 1 \\
\hline Cellular iron ion homeostasis & 0006879 & - & - & - & 1 & 1 & - \\
\hline Heme biosynthetic process & 0006783 & - & - & - & 1 & 1 & - \\
\hline Cellular calcium ion homeostasis & 0006874 & - & - & - & 1 & 1 & - \\
\hline Synaptic transmission & 0007268 & - & - & - & 3 & 3 & - \\
\hline
\end{tabular}

Microarray analyses of $\mathrm{m}$. gastrocnemius from 12-week-old male mice that were either sham-operated or orchidectomized (orx) and treated for 5 weeks with vehicle (veh), dihydrotestosterone (DHT) (45 $\mu \mathrm{g} /$ day), or $17 \beta$-estradiol $\left(E_{2}\right)(0 \cdot 05 \mu \mathrm{g} /$ day). A gene was considered regulated if it demonstrated a fold change $\geq 1 \cdot 5$ and $P \leq 0.05$ (t-test) in response to $\mathrm{E}_{2}$ or DHT treatment compared with the vehicle, $n=5$ in each group. GO ID, gene ontology biological process identity nos. 
Table 2 Regulated genes in common for $17 \beta$-estradiol $\left(\mathrm{E}_{2}\right)$ and dihydrotestosterone (DHT) treatments in mouse skeletal muscle

Fold change

\begin{tabular}{|c|c|c|c|c|}
\hline & \multirow[b]{2}{*}{ Symbol } & \\
\hline & & $\mathrm{E}_{2}$ & $\mathrm{DHT}$ & Function \\
\hline \multicolumn{5}{|l|}{ Gene } \\
\hline FK506-binding protein 5 & Fkbp5 & $1 \cdot 8^{*}$ & $1 \cdot 8^{*}$ & Protein post-translational modification \\
\hline F-box protein 32 & Fbxo32 & $1 \cdot 6^{\dagger}$ & $2 \cdot 2^{*}$ & Protein degradation \\
\hline Potassium voltage-gated channel, subfamily Q, member 5 & Kcnq5 & $2 \cdot 6^{\star}$ & $2 \cdot 3^{*}$ & Ion/substrate transport \\
\hline Ribosomal protein S6 kinase, polypeptide 5 & Rps6ka5 & $1 \cdot 5^{\star}$ & $1 \cdot 6^{\dagger}$ & Transcription \\
\hline Nudix-type motif 18 & Nudt18 & $1 \cdot 6^{\star}$ & $1 \cdot 9^{*}$ & Unknown \\
\hline CDKN2A interacting protein N-terminal like & Cdkn2aipnl & $1 \cdot 6^{\star}$ & $1 \cdot 6^{\dagger}$ & Unknown \\
\hline Phosphodiesterase 4D interacting protein & Pde4dip & $1 \cdot 6^{\star}$ & $1 \cdot 5^{\dagger}$ & Unknown \\
\hline \multicolumn{5}{|c|}{ Down-regulated genes in common after $\mathrm{E}_{2}$ and $\mathrm{DHT}$ treatments } \\
\hline Gremlin 2 & Grem2 & $1 \cdot 6^{\dagger}$ & $2 \cdot 4^{*}$ & Signal transduction \\
\hline Myosin, light polypeptide 3 & Myl3 & $1 \cdot 5^{\dagger}$ & $1 \cdot 8^{*}$ & Muscle contraction \\
\hline
\end{tabular}

Microarray analyses of $\mathrm{m}$. gastrocnemius from 12-week-old male mice that were either sham-operated or orchidectomized (orx) and treated for 5 weeks with vehicle (veh), $\mathrm{DHT}$ ( $45 \mu \mathrm{g} /$ day), or $\mathrm{E}_{2}\left(0.05 \mu \mathrm{g} /\right.$ day). Values are given as fold change, $n=5$ in each group. ${ }^{*} P \leq 0.01$ versus vehicle; ${ }^{\dagger} P \leq 0.05$ versus vehicle. $t$-test.

angiogenesis (Table 3). DHT up-regulated Agtrl1, also known as the apelin receptor, which is active during angiogenesis (Table 3).

\section{Synaptic transmission}

Skeletal muscle fibers are innervated by motor neurons, and DHT up-regulated three genes involved in synaptic transmission in muscle: Musk, Lynxl, and Dlgap4 (Table 3).

\section{Heme biosynthetic process}

The transferrin receptor (Tfrc), which maintains cellular iron ion homeostasis by importing iron into the cell, and Alas1, a rate-controlling mitochondrial heme biosynthetic enzyme, were both up-regulated after DHT treatment (Table 3).

\section{Muscle contraction and extracellular matrix structural constituent}

The gene expression of ten myofibrillar proteins was down-regulated after DHT treatment, and that of one myofibrillar protein was down-regulated after $\mathrm{E}_{2}$ treatment (Table 3). Among the genes that encode the structural proteins that constitute the extracellular matrix including tendons, six different collagen genes were up-regulated after DHT treatment, and one gene was down-regulated. A collagen-binding protein lumican was also down-regulated after DHT treatment (Table 3).

\section{Polyamine biosynthesis}

Three rate-limiting polyamine biosynthetic enzymes, $A m d 1, O d c 1$, and Smox, were highly up-regulated after DHT treatment (Table 3).

\section{Verification of microarray results}

To verify the microarray data, the transcript levels of six genes (Igf1, Fbxo32, Grb10, Gpx3, Odc1, and Myl3) were quantified by RT-PCR. Analysis was performed on individual muscle samples, with $18 \mathrm{~S}$ included as an internal control. As shown in Fig. 3, the regulation of all genes, except that of Myl3, was confirmed.

For the RT-PCR experiment, we also included the sham-operated control group which added some further information on the regulation of these genes. The expression of $F b x o 32$ was decreased by $42.3 \%$ after orx $(P<0 \cdot 01$ versus sham, Fig. 3$)$, and it was normalized by both $\mathrm{E}_{2}$ and DHT treatments to orx mice (Fig. 3). Igf1 expression was decreased in orx mice treated with $\mathrm{E}_{2}$ $(-54.8 \%, P<0.01$ versus sham and $-48.5 \%, P<0.05$ versus orx), while orx by itself or DHT treatment to orx mice had no effect (Fig. 3). Orx resulted in an increase in $G r b 10$ expression $(43.3 \%, P<0.01$ versus sham, Fig. 3), which was normalized by DHT treatment but not by $\mathrm{E}_{2}$ treatment to orx mice. Orx and DHT had no effect on $G p \times 3$ expression, but $\mathrm{E}_{2}$ treatment to orx mice resulted in a dramatic increase $(251 \%, P<0 \cdot 01$ versus sham and $225 \%, P<0.01$ versus orx, Fig. 3). Orx resulted in a decrease in Odc1 expression $(-52 \%$, $P<0.01$ versus sham, Fig. 3), which was normalized by DHT treatment but not by $\mathrm{E}_{2}$ treatment to orx mice. 
Table 3 Regulated genes in mouse skeletal muscle after $17 \beta$-estradiol $\left(E_{2}\right)$ and dihydrotestosterone (DHT) treatments in selected functional categories of importance for skeletal muscle function and development

Gene symbol

\section{Gene title}

Genes regulated after $E_{2}$ treatment

IGF1 signalling

Insulin-like growth factor 1

TBC1 domain family, member 1

Fuel metabolism

Pyruvate carboxylase

Fructose bisphosphatase 2

Carboxylesterase 3

Stearoyl-coenzyme A desaturase 1

Glutathione metabolic process

Glutathione peroxidase 3

Angiogenesis

Angiopoietin 1

Thrombospondin 1

Muscle contraction

Myosin, light polypeptide 3

Genes regulated after DHT treatment

IGF1 signalling

Growth factor receptor-bound protein 10

Suppressor of cytokine signaling 2

Protein tyrosine phosphatase, non-receptor type 11

Fuel metabolism

3-Oxoacid CoA transferase 1

Niemann-Pick type C1

Very low-density lipoprotein receptor

Mitochondrial ATP synthesis-coupled proton transport

$\mathrm{NADH}$ dehydrogenase (ubiquinone) $\mathrm{Fe}-\mathrm{S}$ protein 4

Carbonyl reductase 2

Glutathione metabolic process

Glutathione S-transferase mu 2

Microsomal glutathione S-transferase 3

Microsomal glutathione $S$-transferase 1

Angiogenesis

Angiotensin receptor-like 1

Synaptic transmission

Muscle, skeletal, receptor tyrosine kinase

Ly6/neurotoxin 1

Discs, large homolog-associated protein 4

Heme biosynthetic process

Transferrin receptor

Aminolevulinic acid synthase 1

Polyamine biosynthesis

S-Adenosylmethionine decarboxylase

Ornithine decarboxylase, structural 1

Spermine oxidase

Muscle contraction

Myosin, light polypeptide 3

Myosin, heavy polypeptide 6

Troponin I

Myosin, light polypeptide 2

Troponin C

Myosin, heavy polypeptide 7

Actin, $\alpha$, cardiac muscle 1

Myosin-binding protein $\mathrm{H}$

Troponin T1

Tropomyosin 3

Extracellular matrix structural constituent

Collagen, type I, $\alpha 1$

Collagen, type V, $\alpha 2$

Collagen, type I, $\alpha 2$



Fold change Down/up

$\boldsymbol{P}$

0.038

0.01

0.012

0.01

0.01

$<0.01$

$0 \cdot 017$

0.011

$<0.01$

$<0.01$

0.01

$<0.01$

0.01

$<0.01$

$<0.01$

0.01

$<0.01$

$<0.01$

0.01

0.015

(continued) 
Table 3 Continued

\begin{tabular}{|c|c|c|c|c|}
\hline & Gene symbol & Fold change & Down/up & $P$ \\
\hline \multicolumn{5}{|l|}{ Gene title } \\
\hline $\begin{array}{l}\text { Collagen, type III, } \alpha 1 \\
\text { Collagen, type IV, } \alpha 2 \\
\text { Collagen, type IV, } \alpha 1 \\
\text { Lumican } \\
\text { Collagen, type XIV, } \alpha 1\end{array}$ & $\begin{array}{l}\text { Col3a1 } \\
\text { Col4a2 } \\
\text { Col4a1 } \\
\text { Lum } \\
\text { Col14a1 }\end{array}$ & $\begin{array}{l}1 \cdot 8 \\
1 \cdot 9 \\
2 \cdot 2 \\
1 \cdot 7 \\
1 \cdot 7\end{array}$ & $\begin{array}{l}\text { Up } \\
\text { Up } \\
\text { Up } \\
\text { Down } \\
\text { Down }\end{array}$ & $\begin{aligned} & 0.013 \\
< & 0.01 \\
< & 0.01 \\
< & 0.01 \\
< & 0.01\end{aligned}$ \\
\hline
\end{tabular}

Regulated genes after $\mathrm{E}_{2}$ and DHT treatments in IGF1 signaling, fuel metabolism, mitochondrial ATP synthesis-coupled proton transport, glutathione metabolic process, angiogenesis, synaptic transmission, heme biosynthetic process, polyamine biosynthesis, muscle contraction, and extracellular matrix structural constituents. Microarray analyses of $\mathrm{m}$. gastrocnemius from 12-week-old male mice that were either sham-operated or orchidectomized (orx) and treated for 5 weeks with vehicle (veh), DHT (45 $\mu \mathrm{g} /$ day), or $\mathrm{E}_{2}(0.05 \mu \mathrm{g} /$ day). Values are given as fold change, $n=5$ in each group. $t$-test.

\section{Time course study of regulated genes}

To determine the short-term effects of the hormone treatments on the expression of selected genes in muscle, an experiment with a treatment period of only 1 week was performed. After 1-week treatment, the expression of $F b x o 32$ was increased in $\mathrm{m}$. gastrocnemius (72\%, $P<0.01$ versus sham, Fig. 4A). There was a tendency to normalization of Fbxo32 expression levels with $\mathrm{E}_{2}$ and DHT, but it did not reach statistical significance (Fig. 4A). For comparison, we analyzed m. levator ani, a fast-twitch muscle known to be testosterone dependent in rodents. The effect on Fbxo32 expression was much more dramatic in $\mathrm{m}$. levator ani, although in the same direction as in $\mathrm{m}$. gastrocnemius, and DHT by itself could completely normalize Fbxo32 expression levels after orx (Fig. 4B). The higher levels of Fbxo32 in m. gastrocnemius after orx were only transient, and after 5-week treatment, the levels were similar for the orx group compared with the orx


Figure 3 To verify the microarray data, the transcript levels of six genes (Igf1, Fbxo32, Grb10, Gpx3, Odc1, and Myl3) were quantified by RT-PCR. Analysis was performed on individual muscle samples from 12-week-old male mice that were either sham-operated or orchidectomized (orx) and then treated for 5 weeks with vehicle (veh), dihydrotestosterone (DHT) $\left(45 \mu \mathrm{g} /\right.$ day), or $17 \beta$-estradiol $\left(E_{2}\right)(0.05 \mu \mathrm{g} /$ day). $18 \mathrm{~S}$ was included as an internal control. Data are expressed as percentage of Orx, and are presented as means \pm S.E.M., $n=4-8$ in each group. * $P \leq 0.01$ versus sham; ${ }^{\dagger} P \leq 0.01$ versus orx + veh; ${ }^{\ddagger} P \leq 0.05$ versus sham; ${ }^{\S} P \leq 0.05$ versus orx + veh; ${ }^{\sharp} P \leq 0.01$ versus orx $+E_{2} ;{ }^{€} P \leq 0.05$ versus orx $+E_{2}$. Microarray data are shown for comparison. 



Figure 4 Time course study for Fbxo32 expression in muscle. RT-PCR analysis was performed on individual muscle samples from 12-week-old male mice that were either sham-operated or orchidectomized (orx) and then treated for 1 (A and $B$ ) or $5(C)$ weeks with vehicle (veh), dihydrotestosterone (DHT) (45 $\mu \mathrm{g} /$ day), or $17 \beta$-estradiol $\left(E_{2}\right)(0.05 \mu \mathrm{g} /$ day $)$. Fbxo32 expression in $\mathrm{m}$. gastrocnemius $(A)$ and $\mathrm{m}$. levator ani $(B)$ is presented after 1-week treatment for comparison and in $\mathrm{m}$. gastrocnemius (C) after 5-week treatment. Fbxo32 mRNA levels are corrected for the expression of $18 \mathrm{~S}$, and are presented as means \pm S.E.M., $n=4-8$ in each group. ${ }^{*} P \leq 0.01$ versus sham; ${ }^{\dagger} P \leq 0.01$ versus orx + veh; ${ }^{\ddagger} P \leq 0.05$ versus sham; ${ }^{\S} P \leq 0.05$ versus orx + veh; ${ }^{\#} P \leq 0.01$ versus orx $+\mathrm{E}_{2}$. group after 1-week treatment but had increased for all other groups (Fig. 4C). For the other four genes that were analyzed (Igf1, Grb10, Gpx3, and $O d c 1)$, there was no major difference in expression pattern between 1- and 5-week treatments (Table 4). There was no weight difference in $\mathrm{m}$. gastrocnemius between different treatment groups in the 1-week experiment (data not shown).

\section{Discussion}

Testosterone treatment of orx mice has previously been shown to induce a dose-dependent increase in the mass of individual muscles (Axell et al. 2006). However, how much of this effect is through aromatization of testosterone to $\mathrm{E}_{2}$ is unknown. To differentiate between the direct effects of testosterone and those of testosterone aromatized to $\mathrm{E}_{2}$ on muscle mass, we treated orx mice with $\mathrm{E}_{2}$ and the non-aromatizable androgen DHT. Although the effect of DHT was more marked, both treatments prevented loss of muscle mass after gonadectomy, indicating that AR- and ER-mediated signaling has effects on muscle mass that are independent of each other. The doses used were likely in the physiological range as DHT completely prevented the orx-induced loss of seminal vesicle weight, and $\mathrm{E}_{2}$ and DHT almost completely prevented the orx-induced reduction in trabecular vBMD.

To investigate the mechanism underlying the effect on muscle mass, we performed microarray and RT-PCR analyses on skeletal muscle samples. In line with a more profound effect of DHT on muscle mass, the microarray analyses demonstrated that a greater number of genes were regulated after DHT treatment $(n=187)$ than after $\mathrm{E}_{2}$ treatment $(n=51)$. Thirteen genes were regulated by both $\mathrm{E}_{2}$ and DHT, and these could represent mechanisms in common for how activation of AR and ER signaling stimulates skeletal muscle mass. However, the results indicate that most of the effects of $E_{2}$ and DHT in skeletal muscle of male mice are mediated by different mechanisms. Even when $\mathrm{E}_{2}$ and DHTaffected the same pathways, such as IGF1 signaling, increased angiogenesis, and glutathione oxidation, it was done by regulating different sets of genes.

\section{Regulated genes in common for DHT and $E_{2}$}

Among the eight genes with known function that were regulated by both DHT and $\mathrm{E}_{2}$, increased expression was observed for Kcnq5, which encodes a potassium channel that is involved in skeletal muscle cell proliferation by triggering changes in membrane potential and regulating cell volume (Roura-Ferrer et al. 2008). Surprisingly, Fbxo32, a gene encoding a muscle-specific F-box protein implicated in muscle 
Table 4 Time course study for the expression of regulated genes in muscle. Data are expressed as percentage of orchidectomized (Orx), and are presented as means \pm S.E.M., $n=4-8$ in each group

One-week treatment

\begin{tabular}{|c|c|c|c|c|c|c|c|}
\hline Sham & Orx veh & $E_{2}$ & DHT & Sham & Orx veh & $E_{2}$ & DHT \\
\hline $137 \pm 15$ & $100 \pm 16^{\ddagger}$ & $42 \pm 5^{\star, \S}$ & $93 \pm 12^{\ddagger, \|}$ & $114 \pm 10$ & $100 \pm 14$ & $52 \pm 7^{*, \S}$ & $82 \pm 11^{\pi}$ \\
\hline $71 \pm 4$ & $100 \pm 4^{*}$ & $70 \pm 3^{\dagger}$ & $57 \pm 4^{\ddagger, t, \oplus}$ & $70 \pm 6$ & $100 \pm 7^{*}$ & $98 \pm 7^{*}$ & $55 \pm 4^{\dagger, \|}$ \\
\hline $112 \pm 11$ & $100 \pm 10$ & $274 \pm 11^{*, \dagger}$ & $75 \pm 12^{\|}$ & $92 \pm 10$ & $100 \pm 7$ & $325 \pm 24^{*}, \dagger$ & $89 \pm 4^{\| \prime}$ \\
\hline $159 \pm 12$ & $100 \pm 5^{*}$ & $80 \pm 5^{*}$ & $193 \pm 30^{\dagger, \|}$ & $210 \pm 29$ & $100 \pm 6^{*}$ & $90 \pm 6^{*}$ & $226 \pm 33^{t, \|}$ \\
\hline
\end{tabular}

Time course study for the expression of five genes (Igf1, Fbxo32, Grb10, Gpx3, and Odc1) by RT-PCR. Analysis was performed on individual muscle samples from 12-week-old male mice that were either sham-operated or orx and then treated for 1 or 5 weeks with vehicle (veh), dihydrotestosterone (DHT) (45 $\mu \mathrm{g} /$ day), or $17 \beta$-estradiol $\left(E_{2}\right)\left(0.05 \mu \mathrm{g} /\right.$ day). $18 \mathrm{~S}$ was included as an internal control. ${ }^{\star} P \leq 0.01$ versus sham; ${ }^{\dagger} P \leq 0.01$ versus orx + veh; ${ }^{\ddagger} P \leq 0.05$ versus sham; ${ }^{\S} P \leq 0.05$ versus orx + veh; " $P \leq 0.01$ versus orx $+E_{2} ;{ }^{\circledR} P \leq 0.05$ versus orx $+E_{2}$.

atrophy, was up-regulated by both treatments. The RT-PCR analyses demonstrated that this up-regulation was a normalization of Fbxo32 expression to the same levels as in the sham-operated controls. In multiple models of skeletal muscle atrophy, Fbxo32 is up-regulated, and it appears to be essential for accelerated muscle protein degradation in a variety of experimental models of catabolism, including diabetes, cancer, AIDS, fasting, renal failure, hindlimb suspension, immobilization, oxidative stress, and sepsis (Sacheck et al. 2007). In a recent study done by Pires-Oliveira et al. (2010), Fbxo32 expression was high in rat $\mathrm{m}$. levator ani over a week after castration, and this increase could be reversed by treatment with testosterone. Interestingly, in another recent study done by Rogers et al. (2010), mice showed decreased expression of Fbxo32 12 weeks after castration similar to what was observed in our study. In a short-term experiment of only 1 week, we could show that these seemingly contradictory results depend on the fact that the increase of Fbxo32 with gonadectomy is only transient and could be partly reversed by treatment with $\mathrm{E}_{2}$ and fully reversed by treatment with DHT in m. levator ani. After a 5-week treatment period, the levels of Fbxo32 had increased in all groups but stayed on similar levels in the orx groups. The transient increase of Fbxo 32 probably reflects that accelerated muscle loss occurs early and transiently after castration, and that at least in $\mathrm{m}$. levator ani, which is a fast-twitch muscle, this loss can be partly prevented by $\mathrm{E}_{2}$ and fully prevented by DHT.

The size of pre-existing muscle fibers is decreased in skeletal muscle atrophy, and in line with this, one myofibrillar protein was decreased after both DHT and $\mathrm{E}_{2}$ treatments and ten myofibrillar proteins were decreased after DHT treatment alone, despite the observed prevention of loss in muscle mass. Our hypothesis is that a decrease in muscle mass probably occurs very early after orx, and that the biosynthesis and breakdown of myofibrillar proteins have began to enter, or already reached, a new steady state after 4 weeks.

\section{Extracellular matrix structural constituents}

Collagens are the main proteins of the extracellular matrix including tendons that surround and support muscle fibers. The expression of six different collagen genes was up-regulated after DHT treatment, indicating that synthesis of more extracellular matrix was an ongoing process. The GH/IGF1 axis exerts, like testosterone and $\mathrm{E}_{2}$, anabolic effects on lean body mass. In a previous study, in which muscle biopsies were analyzed using microarray before and after 2-week GH treatment to hypopituitary men with hypogonadism, we also observed increased synthesis of collagens and a decreased expression of several myofibrillar proteins (Sjogren et al. 2007).

\section{IGF1 signaling}

IGF1 is a potent anabolic agent in muscle (Musaro et al. 2001). After $E_{2}$ treatment, the importance of the observed changes in the IGF1 system for muscle function was not clear as serum levels of IGF1 were increased, whereas the local gene expression of Igfl in muscle was reduced. However, increased serum IGF1 levels have also been observed in postmenopausal women treated with transdermal $\mathrm{E}_{2}$ (Weissberger et al. 1991, Ho et al. 2003).

DHT treatment decreased the expression of Grb10, a negative regulator of IGF1 signaling (Dufresne \& Smith 2005). In line with IGF1 being an anabolic agent in muscle, mice with a disrupted Grb10 gene have increased muscle and lean mass (Smith et al. 2007). The RT-PCR analyses showed that DHT but not $\mathrm{E}_{2}$ could normalize Grb10 expression after orx, indicating that this is an AR-mediated effect. Interestingly, the expression of Grb10 in muscle has been shown to be gender dependent with higher expression in women than in men, suggesting a role for Grb10 in the sexual dimorphism of skeletal muscle mass (Welle et al. 2008). Furthermore, DHT reduced the expression of the Socs 2 gene in muscle. SOCS2 reduces GH signaling; therefore, a down-regulation of Socs 2 expression in muscle 
likely increases the effect of GH/IGF1 locally in muscle. Together these indicate that the AR-mediated effects on muscle mass include increased local effect of GH/IGF1 by a down-regulation of Grb10 and Socs 2 .

\section{Angiogenesis}

Increased angiogenesis would result in improved microcirculation in muscle, and hence would provide an increased oxygen and nutrient supply as well as lead to the removal of waste products. $\mathrm{E}_{2}$ up-regulated Angpt1, an angiogenesis promoter during embryonic development, essential to endothelial cell survival, vascular branching, and pericyte recruitment (Carmeliet 2000). Furthermore, $\mathrm{E}_{2}$ down-regulated Thbs1, a potent angiogenesis inhibitor (Lawler 2002). Agtrl1 or the apelin receptor was up-regulated by DHT. Apelin through its receptor AGTRL1 is involved in the regulation of blood vessel diameter during angiogenesis, and apelin-deficient mice showed narrow blood vessels during embryogenesis (Kidoya et al. 2008). Together these results point to increased angiogenesis in muscle after both $\mathrm{E}_{2}$ and DHT treatments.

\section{Glutathione metabolism}

Both $\mathrm{E}_{2}$ and DHT increased the expression of genes in the glutathione metabolic pathway that protects cells from oxidative damage. One of these genes, $G p \times 3$, was markedly up-regulated in muscle by $\mathrm{E}_{2}$. Gpx3 has earlier been shown to be directly regulated by $\mathrm{E}_{2}$ in white adipose tissue (Lundholm et al. 2008). Gpx3 improves skeletal muscle insulin sensitivity by mediating the antioxidant effect of PPAR $\gamma$ (PPARG; Chung et al. 2009), and increased glutathione peroxidase activity could mediate the improvement of muscle strength by selenium treatment in selenium-deficient patients (Brown et al. 1986).

\section{Fuel metabolism}

$\mathrm{E}_{2}$ had effects on genes regulating intermediary glucose and lipid metabolism. Pyruvate carboxylase, a mitochondrial protein that is important for intermediary metabolism by catalyzing the carboxylation of pyruvate to form oxaloacetate, was strongly up-regulated by $\mathrm{E}_{2}$. Oxaloacetate is an intermediate of the citric acid cycle and glyconeogenesis. Fbp2, expressing an enzyme that catalyzes the hydrolysis of fructose-1,6-bisphosphate into fructose-6-phosphate and is critical in glyconeogenesis pathway, was also up-regulated after $\mathrm{E}_{2}$ treatment, indicating increased glycogen synthesis in muscle. Ces3, which mediates some or all of the lipolysis that is independent of hormone-sensitive lipase (Soni et al. 2004), was up-regulated in muscle by $\mathrm{E}_{2}$, indicating increased utilization of free fatty acids as fuel.

\section{Synaptic transmission}

DHT up-regulated several genes involved in synaptic transmission in muscle, among them was Musk, which encodes a receptor tyrosine kinase that is essential for synapse formation and the development of new neuromuscular junctions (Kim \& Burden 2008), indicating a role for AR-mediated signaling in this process.

\section{Heme biosynthetic process}

DHT also affected the expression in muscle of genes important for the supply of oxygen. Iron, which is essential for oxygen transport because it is incorporated in the heme of the oxygen-binding proteins hemoglobin and myoglobin, is delivered to cells via binding to the Tfrc (Xu et al. 2005). Tfrc together with Alas1, a rate-controlling mitochondrial heme biosynthetic enzyme, was up-regulated after DHT treatment, suggesting increased heme biosynthesis.

\section{Polyamine biosynthesis}

Three rate-limiting polyamine biosynthetic enzymes, Amd1, Odc1, and Smox, were highly up-regulated after DHT treatment. In a study measuring the short-term effects of DHT on gene expression in muscle of castrated mice, genes involved in polyamine synthesis were also up-regulated, indicating a direct effect of DHT on this process (Yoshioka et al. 2006). Data suggest that polyamines play a role in muscle hypertrophy, although their mechanisms of action are still unknown (Abukhalaf et al. 2002). Furthermore, male ARKO mice have impaired skeletal muscle development and function, which were associated with decreased expression of polyamine biosynthetic enzymes (MacLean et al. 2008). This indicates a role for these enzymes in the AR-mediated effects on muscle.

In conclusion, activation of both $\mathrm{ER}$ and $\mathrm{AR}$ preserves muscle and lean mass after gonadectomy in male mice, although the effect was more marked after $\mathrm{AR}$ activation. Few genes were regulated by both $\mathrm{E}_{2}$ and DHT, and when $\mathrm{E}_{2}$ and DHT regulated the same pathways (IGF1 signaling, increased angiogenesis, and glutathione oxidation), it was done by affecting different sets of genes. However, short-term treatment with $\mathrm{E}_{2}$ partly prevented and with DHT fully prevented the transient increase in Fbxo32 expression observed after gonadectomy. $\mathrm{E}_{2}$ alone had effects on genes involved in glucose and lipid metabolism, likely increasing glycogen synthesis and utilization of FAs for fuel in muscle. DHT alone regulated the expression of genes influencing synaptic formation and transmission, oxygen transport, and polyamine biosynthesis. Based on these findings, it could be hypothesized that the metabolic effects of testosterone in skeletal 
muscle of male mice are to a large extent dependent on ER activation, whereas other effects of testosterone in skeletal muscle are more dependent on AR activation.

\section{Supplementary data}

This is linked to the online version of the paper at http://dx.doi.org/ 10.1677/JME-09-0165.

\section{Declaration of interest}

The authors declare that there is no conflict of interest that could be perceived as prejudicing the impartiality of the research reported.

\section{Funding}

This study was supported by the Swedish Research Council, the Swedish Foundation for Strategic Research, the ALF/LUA research grant in Gothenburg, the Lundberg Foundation, the Torsten and Ragnar Söderberg's Foundation, the Novo Nordisk Foundation, the Magnus Bergvall Foundation, the Ake Wiberg Foundation, the Tore Nilsson Foundation, and the Swedish Society for Medical Research.

\section{References}

Abukhalaf IK, von Deutsch DA, Wineski LE, Silvestrov NA, Abera SA, Sahlu SW \& Potter DE 2002 Effect of hindlimb suspension and clenbuterol treatment on polyamine levels in skeletal muscle. Pharmacology 65 145-154.

Axell AM, MacLean HE, Plant DR, Harcourt LJ, Davis JA, Jimenez M, Handelsman DJ, Lynch GS \& Zajac JD 2006 Continuous testosterone administration prevents skeletal muscle atrophy and enhances resistance to fatigue in orchidectomized male mice. American Journal of Physiology. Endocrinology and Metabolism 291 E506-E516.

Barros RP, Machado UF, Warner M \& Gustafsson JA 2006 Muscle GLUT4 regulation by estrogen receptors ERbeta and ERalpha. PNAS 103 1605-1608.

Brown MR, Cohen HJ, Lyons JM, Curtis TW, Thunberg B, Cochran WJ \& Klish WJ 1986 Proximal muscle weakness and selenium deficiency associated with long term parenteral nutrition. American Journal of Clinical Nutrition 43 549-554.

Brown M, Foley A \& Ferreria JA 2005 Ovariectomy, hindlimb unweighting, and recovery effects on skeletal muscle in adult rats. Aviation, Space, and Environmental Medicine 76 1012-1018.

Carmeliet P 2000 Mechanisms of angiogenesis and arteriogenesis. Nature Medicine 6 389-395.

Chen Y, Zajac JD \& MacLean HE 2005 Androgen regulation of satellite cell function. Journal of Endocrinology 186 21-31.

Chung SS, Kim M, Youn BS, Lee NS, Park JW, Lee IK, Lee YS, Kim JB, Cho YM, Lee HK et al. 2009 Glutathione peroxidase 3 mediates the antioxidant effect of peroxisome proliferator-activated receptor \{gamma\} in human skeletal muscle cells. Molecular and Cellular Biology 29 20-30.

Dufresne AM \& Smith RJ 2005 The adapter protein GRB10 is an endogenous negative regulator of insulin-like growth factor signaling. Endocrinology 146 4399-4409.
Glenmark B, Nilsson M, Gao H, Gustafsson JA, Dahlman-Wright K \& Westerblad H 2004 Difference in skeletal muscle function in males vs. females: role of estrogen receptor-beta. American Journal of Physiology. Endocrinology and Metabolism 287 E1125-E1131.

Ho KK, O'Sullivan AJ, Wolthers T \& Leung KC 2003 Metabolic effects of oestrogens: impact of the route of administration. Annales d'Endocrinologie 64 170-177.

Irizarry RA, Hobbs B, Collin F, Beazer-Barclay YD, Antonellis KJ, Scherf U \& Speed TP 2003 Exploration, normalization, and summaries of high density oligonucleotide array probe level data. Biostatistics 4 249-264.

Kahlert S, Grohe C, Karas RH, Lobbert K, Neyses L \& Vetter H 1997 Effects of estrogen on skeletal myoblast growth. Biochemical and Biophysical Research Communications 232 373-378.

Kidoya H, Ueno M, Yamada Y, Mochizuki N, Nakata M, Yano T, Fujii R \& Takakura N 2008 Spatial and temporal role of the apelin/APJ system in the caliber size regulation of blood vessels during angiogenesis. EMBO Journal 27 522-534.

Kim N \& Burden SJ 2008 MuSK controls where motor axons grow and form synapses. Nature Neuroscience 11 19-27.

Kobori M \& Yamamuro T 1989 Effects of gonadectomy and estrogen administration on rat skeletal muscle. Clinical Orthopaedics and Related Research 243 306-311.

Kong A \& Edmonds P 2002 Testosterone therapy in HIV wasting syndrome: systematic review and meta-analysis. Lancet Infectious Diseases 2 692-699.

Lawler J 2002 Thrombospondin-1 as an endogenous inhibitor of angiogenesis and tumor growth. Journal of Cellular and Molecular Medicine 6 1-12.

Lin HY, Xu Q, Yeh S, Wang RS, Sparks JD \& Chang C 2005 Insulin and leptin resistance with hyperleptinemia in mice lacking androgen receptor. Diabetes 54 1717-1725.

Lundholm L, Putnik M, Otsuki M, Andersson S, Ohlsson C, Gustafsson JA \& Dahlman-Wright K 2008 Effects of estrogen on gene expression profiles in mouse hypothalamus and white adipose tissue: target genes include glutathione peroxidase 3 and cell death-inducing DNA fragmentation factor, alpha-subunit-like effector A. Journal of Endocrinology 196 547-557.

MacLean HE, Warne GL \& Zajac JD 1997 Localization of functional domains in the androgen receptor. Journal of Steroid Biochemistry and Molecular Biology 62 233-242.

MacLean HE, Chiu WS, Notini AJ, Axell AM, Davey RA, McManus JF, Ma C, Plant DR, Lynch GS \& Zajac JD 2008 Impaired skeletal muscle development and function in male, but not female, genomic androgen receptor knockout mice. FASEB Journal 22 2676-2689.

Matsumine H, Hirato K, Yanaihara T, Tamada T \& Yoshida M 1986 Aromatization by skeletal muscle. Journal of Clinical Endocrinology and Metabolism 63 717-720.

McCormick KM, Burns KL, Piccone CM, Gosselin LE \& Brazeau GA 2004 Effects of ovariectomy and estrogen on skeletal muscle function in growing rats. Journal of Muscle Research and Cell Motility 25 21-27.

Moran AL, Nelson SA, Landisch RM, Warren GL \& Lowe DA 2007 Estradiol replacement reverses ovariectomy-induced muscle contractile and myosin dysfunction in mature female mice. Journal of Applied Physiology 102 1387-1393.

Musaro A, McCullagh K, Paul A, Houghton L, Dobrowolny G, Molinaro M, Barton ER, Sweeney HL \& Rosenthal N 2001 Localized Igf-1 transgene expression sustains hypertrophy and regeneration in senescent skeletal muscle. Nature Genetics $\mathbf{2 7}$ 195-200.

Ophoff J, Van Proeyen K, Callewaert F, De Gendt K, De Bock K, Vanden Bosch A, Verhoeven G, Hespel P \& Vanderschueren D 2009 Androgen signaling in myocytes contributes to the maintenance of muscle mass and fiber type regulation but not to muscle strength or fatigue. Endocrinology 150 3558-3566. 
Pires-Oliveira M, Maragno AL, Parreiras-e-Silva LT, Chiavegatti T, Gomes MD \& Godinho RO 2010 Testosterone represses ubiquitin ligases atrogin-1 and Murf-1 expression in an androgen-sensitive rat skeletal muscle in vivo. Journal of Applied Physiology 108 266-273.

Rogers NH, Perfield JW II, Strissel KJ, Obin MS \& Greenberg AS 2010 Loss of ovarian function in mice results in abrogated skeletal muscle PPARdelta and FoxO1-mediated gene expression. Biochemical and Biophysical Research Communications 392 1-3.

Roura-Ferrer M, Sole L, Martinez-Marmol R, Villalonga N \& Felipe A 2008 Skeletal muscle Kv7 (KCNQ) channels in myoblast differentiation and proliferation. Biochemical and Biophysical Research Communications 369 1094-1097.

Sacheck JM, Hyatt JP, Raffaello A, Jagoe RT, Roy RR, Edgerton VR, Lecker SH \& Goldberg AL 2007 Rapid disuse and denervation atrophy involve transcriptional changes similar to those of muscle wasting during systemic diseases. FASEB Journal 21 140-155.

Sitnick M, Foley AM, Brown M \& Spangenburg EE 2006 Ovariectomy prevents the recovery of atrophied gastrocnemius skeletal muscle mass. Journal of Applied Physiology 100 286-293.

Sjogren K, Leung KC, Kaplan W, Gardiner-Garden M, Gibney J \& Ho KK 2007 Growth hormone regulation of metabolic gene expression in muscle: a microarray study in hypopituitary men. American Journal of Physiology. Endocrinology and Metabolism 293 E364-E371.

Smith FM, Holt LJ, Garfield AS, Charalambous M, Koumanov F, Perry M, Bazzani R, Sheardown SA, Hegarty BD, Lyons RJ et al. 2007 Mice with a disruption of the imprinted Grb10 gene exhibit altered body composition, glucose homeostasis, and insulin signaling during postnatal life. Molecular and Cellular Biology 27 5871-5886.

Snyder PJ, Peachey H, Hannoush P, Berlin JA, Loh L, Lenrow DA, Holmes JH, Dlewati A, Santanna J, Rosen CJ et al. 1999 Effect of testosterone treatment on body composition and muscle strength in men over 65 years of age. Journal of Clinical Endocrinology and Metabolism 84 2647-2653.

Snyder PJ, Peachey H, Berlin JA, Hannoush P, Haddad G, Dlewati A, Santanna J, Loh L, Lenrow DA, Holmes JH et al. 2000 Effects of testosterone replacement in hypogonadal men. Journal of Clinical Endocrinology and Metabolism 85 2670-2677.

Soni KG, Lehner R, Metalnikov P, O'Donnell P, Semache M, Gao W, Ashman K, Pshezhetsky AV \& Mitchell GA 2004 Carboxylesterase 3 (EC 3.1.1.1) is a major adipocyte lipase. Journal of Biological Chemistry 279 40683-40689.
Sorensen MB, Rosenfalck AM, Hojgaard L \& Ottesen B 2001 Obesity and sarcopenia after menopause are reversed by sex hormone replacement therapy. Obesity Research 9 622-626.

Trenkle A 1976 The anabolic effect of estrogens on nitrogen metabolism of growing and finishing cattle and sheep. Environmental Quality and Safety. Supplement 5 79-88.

Vandenput L, Boonen S, Van Herck E, Swinnen JV, Bouillon R \& Vanderschueren D 2002 Evidence from the aged orchidectomized male rat model that 17 beta-estradiol is a more effective bone-sparing and anabolic agent than 5alpha-dihydrotestosterone. Journal of Bone and Mineral Research 17 2080-2086.

Weissberger AJ, Ho KK \& Lazarus L 1991 Contrasting effects of oral and transdermal routes of estrogen replacement therapy on 24-hour growth hormone $(\mathrm{GH})$ secretion, insulin-like growth factor I, and GH-binding protein in postmenopausal women. Journal of Clinical Endocrinology and Metabolism 72 374-381.

Welle S, Tawil R \& Thornton CA 2008 Sex-related differences in gene expression in human skeletal muscle. PLoS ONE 3 e1385.

Windahl SH, Vidal O, Andersson G, Gustafsson JA \& Ohlsson C 1999 Increased cortical bone mineral content but unchanged trabecular bone mineral density in female ERbeta $(-/-)$ mice. Journal of Clinical Investigation 104 895-901.

Xu G, Liu R, Zak O, Aisen P \& Chance MR 2005 Structural allostery and binding of the transferrin*receptor complex. Molecular and Cellular Proteomics 4 1959-1967.

Yang LY \& Arnold AP 2000 Interaction of BDNF and testosterone in the regulation of adult perineal motoneurons. Journal of Neurobiology 44 308-319.

Yoshioka M, Boivin A, Ye P, Labrie F \& St-Amand J 2006 Effects of dihydrotestosterone on skeletal muscle transcriptome in mice measured by serial analysis of gene expression. Journal of Molecular Endocrinology 36 247-259.

\section{Received in final form 1 April 2010 \\ Accepted 30 April 2010}

Made available online as an Accepted Preprint 30 April 2010 